\title{
Identification of Plasmodium Species by Multiplex PCR in a Single Tube Reaction
}

\author{
Abisha Jayasingh Chellammal ${ }^{1}$, Vasanthi Rompicherla² Jayanthi Subramaniyan ${ }^{3}$, Chandrasekaran Srinivasan ${ }^{4}$
}

${ }^{1}$ Department of Microbiology, Chettinad Academy of Research and Education, Chennai, Tamilnadu, India. ${ }^{2}$ Department of Microbiology, Chettinad Academy of Research and Education, Chennai, Tamilnadu, India. ${ }^{3}$ Department of Microbiology, Chettinad Academy of Research and Education, Chennai, Tamilnadu, India. ${ }^{4}$ Department of Microbiology, Government Hospital, Thondirper, Chennai, Tamilnadu, India.

\section{ABSTRACT}

\section{BACKGROUND}

Epidemiological studies based on molecular methods for identification of Plasmodium vivax and Plasmodium falciparum is gaining importance, because the conventional methods like microscopy, cannot detect low-level parasitaemia and mixed infections. Even though different types of laboratory investigations for diagnosing malaria-like rapid antigen detection and QBC were developed, still there are some negative interpretations among convalescent cases identified in endemic areas. These issues can be overcome by using molecular techniques like multiplex PCR, nested PCR, real-time PCR and reverse transcriptase PCR. Among these methods real-time PCR has been shown to be more sensitive in studying the epidemiology of malaria. We wanted to standardize Multiplex PCR for the identification of Plasmodium species in a single reaction mix.

\section{METHODS}

A total of 52 blood samples were collected from suspected cases of clinical malaria which were tested for microscopy by using Leishman's stain and confirmed by conventional and multiplex PCR. Standardization of multiplex PCR for the identification of Plasmodium species in a single reaction mix was done for the diagnosis of malaria.

\section{RESULTS}

Out of 52 blood samples collected, about 38 (73.08\%) samples were confirmed with a multiplex PCR technique and only $34(65.38 \%)$ by microscopy. The four samples negative by microscopy were found to be Plasmodium falciparum. A significant correlation was found with the positive samples by conventional and standardized multiplex PCR.

\section{CONCLUSIONS}

Multiplex PCR is more useful for accurate diagnosis and epidemiological study for the detection of various species of the genus Plasmodium in a single-step reaction.

\section{KEY WORDS}

Multiplex PCR, Plasmodium falciparum, Plasmodium vivax, Single Reaction Mix, Microscopy
Corresponding Author: Dr. Vasanthi Rompicherla, Flat No. 1A, Ram Beuan Havens Apts., Natham Link Road, Egattur, Chennai-603103, Tamilnadu, India E-mail: drvasanthisai@gmail.com

DOI: $10.14260 /$ jemds/2020/51

Financial or Other Competing Interests: None.

How to Cite This Article: Chellammal AJ, Rompicherla V, Subramaniyan $J$, et al. Identification of plasmodium species by multiplex PCR in a single tube reaction. J. Evolution Med. Dent. Sci. 2020;9(04):223-226, DOI: $10.14260 /$ jemds $/ 2020 / 51$

Submission 25-11-2019,

Peer Review 07-01-2020,

Acceptance 13-01-2020,

Published 27-01-2020. 


\section{BACKGROUND}

At present, there are five known species of the genus Plasmodium that can infect humans; the word malaria comes from Italian meaning "Bad air."(1) Plasmodia are sporozoan parasites of red blood cells transmitted to animals by the bite of mosquitoes. Among the five species currently known to cause malaria, $P$. malariae was previously misidentified for the fifth species Plasmodium knowlesi which originated from Old World monkeys and this new species was even notified outside Asia.(2) Plasmodium falciparum and Plasmodium vivax are common in South India. According to the latest World malaria report, released in November 2018, there were 219 million cases of malaria in 2017 and 217 million cases in 2016. The development of outbreaks of new species of Plasmodium may be due to natural calamities and wars that change the ecosystem, increase in vector population and migration of the human population. These factors have an effect on the immune status of humans leading to variations in endemicity thus making prevention, diagnosis, and treatment of malaria a challenging aspect.(2)

According to $\mathrm{WHO}$, the African region carries a disproportionately high share of the global malaria burden. As per WHO, P. falciparum accounts for $99.7 \%$ of estimated malaria cases in the African Region, in South-East Asia 62.8\%, in the Eastern Mediterranean it was found to be $69 \%$ and in the Western Pacific 71.9\%, in the year 2017. Plasmodium vivax is the predominant parasite in the WHO Region of the American continent, representing $74.1 \%$ of malaria cases. ${ }^{(3,4)}$ According to the survey done in 2017, forty-nine percent of malaria cases were reported in the following countries, Nigeria 25\%, the Democratic Republic of the Congo $11 \%$, Mozambique $5 \%$, in India and Uganda it was $4 \%$ each.(5) According to the National Vector Borne Disease Control Program, in India until May 2019 the total malaria cases were estimated to be 66,313 , out of the P. falciparum were 38,020 resulting in 13 deaths. In Tamil Nadu, 284 reported cases were belonging to $P$. falciparum, out of a total of 553 malaria cases with no incidence of deaths. (6) India and Uganda come under highly endemic countries for malaria, they recently showed a significant decrease in malaria cases after the goal set up by The Global Technical Strategy for Malaria 2016-2030, which was adopted by the World Health Assembly in May 2015. The main aim of this strategy is to bring down the world malaria mortality and incidence by $90 \%$ by the year $2030 .(1)$

Several malaria-endemic African countries exhibit genetic diversity when compared to countries in Central and South America even though the intensity of Plasmodium falciparum transmission is the same. Novel studies are necessary to evaluate the genotype circulating in different regions by molecular methods.(7) According to a research study, microscopy was proved to be less sensitive when compared to molecular methods like single-step PCR, loop-mediated isothermal amplification (LAMP) assay, nested PCR, multiplex PCR, and real-time PCR.(3) Antigen detection and molecular amplification methods have gained significance as newer diagnostic tools with more sensitive results and can be implemented as better point of care diagnostic tests, especially in antigenic variants of Plasmodium species and hypnozoites of Plasmodium vivax.(7) Worldwide several attempts were made to improve the quality and specificity of various diagnostic methods towards the malaria eradication program. Studies showed tools designed using single-tube PCR methods targeting mitochondrial enzymes with hybridization techniques, these attempts were successful and are found to be 40 times more sensitive in the detection of single as well as mixed species of Plasmodium infections than the conventional PCR. (8) Methods to decrease the time limit by molecular methods was also made by "fast PCR enzyme" using two sets of primers targeting the ribosomal RNA genes by nested PCR method, which can identify the newly evolving species of Plasmodium and the results were found to be consistent with the routine microscopic method. This new method required only 65 minutes for the two steps.(9) In a study by Mayra et al in 2018 a comparison was made among microscopy, serological and molecular techniques in Brazil for identification of Plasmodium species from the blood samples collected from non-human primates (NHPS). In his study microscopy was found to be a less sensitive method, especially in primates of low parasitaemia levels, and hence there is a chance of misdiagnosis of Plasmodium species. Rapid antigen detection methods were considered as alternatives for non-human primates for the detection of Plasmodium species as they can detect only two predominant species. ELISA methods were proved to be least sensitive, whereas the latest lamp assay was able to detect parasitaemia levels of 5 parasites $/ \mu$ l, methods like real-time PCR was able to detect up to 0.5 parasites $/ \mu \mathrm{l}$, and best results were found with semi-nested PCR which was able to detect as low as 0.01 parasites $/ \mu$ in a single reaction mixture. Further attempts made in research to study the human as well as non-human primate population for malarial infection may help in the development of vaccines, drugs and new prevention measures which will help in reconsidering malaria as a neglected tropical disease.(2) The identification of various genetic determinants can be considered as molecular markers for surveillance; the present study is done to standardize multiplex PCR for the detection of Plasmodium species in a single step reaction mixture.(10)

\section{METHODS}

It was a cross-sectional study conducted in Chettinad Hospital and Research Institute, Kelambakkam, from Jan 2019 to Aug. 2019. Since it was not a prevalence study the sample size was not considered. A total of 52 blood samples were collected from patients with a history of fever, chills, and rigors, with suspected malaria attending various outpatient departments. The informed written consent was obtained from the participating patients with their knowledge of the aim of our study. Institutional Human Ethical committee approval for the proposal was obtained with the no: 361/IHEC/1-19 on Jan. 2019.

\section{Sample Collection}

A total of 52 blood samples were collected. About $2 \mathrm{ml}$ of blood was collected by venipuncture from patients in an EDTA vacutainer under aseptic conditions, each sample was examined by performing a thin smear with Leishman's staining method and later confirmed by multiplex PCR. 


\section{Molecular Detection}

The DNA extraction was done from all the 52 blood samples after microscopic confirmation and was evaluated for polymerase chain reaction for species identification. The cycles were standardized from previous studies done by Weon Gyn Kho et al 2003 and Omima et al 2016 for conventional and duplex PCR respectively, (11,12) the primers were purchased from Sigma Aldrich Chemical Pvt Ltd. The blood samples with clot formation and those stored for a prolonged period were not considered for this study.

\section{DNA Extraction}

Parasitic DNA was extracted from fresh whole blood samples by using the QIAamp DNA Mini Kit (Qiagen) Kit method, the extracted DNA was dissolved in TE buffer and stored without contamination at $-20^{\circ} \mathrm{C}$ until further use.

\begin{tabular}{|c|c|c|}
\hline Specific Region & Sequences & $\begin{array}{l}\text { Base } \\
\text { Pairs }\end{array}$ \\
\hline Universal forward & 5-TCAGCTTTTGATGTTAGGGTATT-3, & \\
\hline Plasmodium vivax reverse & 5'TAAACTCCGA & $33 \mathrm{bp}$ \\
\hline Plasmodium falciparum reverse & 5'GCATCAAAGATACAAATATAAGC- $3{ }^{`}$ & $1451 \mathrm{bp}$ \\
\hline Plasmodium malariae & $\begin{array}{l}\text { 5'ATAACATAGTTGTACGTTAAGAATAACCGC-3`' } \\
\text { 5'AAAATTCCCATGCATAAAAAATTATACAAA-3`' }\end{array}$ & $145 \mathrm{bp}$ \\
\hline Plasmodium ovale & $\begin{array}{l}\text { 5`TGTAGTATTCAAACGCAGT-3`' } \\
\text { 5'TATGTACTTGTTAAGCCTTT-3` }\end{array}$ & $659 \mathrm{bp}$ \\
\hline
\end{tabular}

\section{Conventional Uniplex PCR}

The above primers were used for the conventional PCR for the identification of various Plasmodium species individually. A single universal forward primer and a pair of reverse primers designed from the genus-specific region of $P$. falciparum and P. vivax along with two sets of forward and reverse primers for the $P$. ovale and $P$. malariae were picked from previous articles The PCR reaction mix of $15 \mu$ l was used, which includes $12.5 \mu \mathrm{l}$ of Emerald master mix, $1 \mu \mathrm{l}$ of template DNA, $0.5 \mu \mathrm{l}$ of $\mathrm{dH}_{2} 0,0.5 \mu \mathrm{l}$ forward and reverse primers each for four different the species of Plasmodium as separate reactions.

\section{Multiplex PCR}

All the four primers were included in the reaction mixture for the multiplex PCR. A total of $30 \mu \mathrm{l}$ reaction mixture was used, which includes $20 \mu \mathrm{l}$ of Emerald master mix, $2 \mu \mathrm{l}$ of template DNA, $1 \mu \mathrm{l}$ each primer of the four species and $1 \mu \mathrm{l}$ of $\mathrm{dH}_{2} 0$.

\section{Multiplex PCR with Single Reaction Mixture for Species Identification \\ The primers of both Plasmodium falciparum and Plasmodium vivax were included in the same reaction mixture for performing the single reaction mix multiplex PCR along with the pooled DNA extracts. About two positive samples each of Plasmodium falciparum and Plasmodium vivax as two sets, confirmed by Conventional Multiplex PCR were used. A total of $30 \mu \mathrm{l}$ reaction mixture was used, which includes $22 \mu \mathrm{l}$ of Emerald master mix, $2 \mu \mathrm{l}$ of Plasmodium falciparum and Plasmodium vivax template DNA each and, $1 \mu \mathrm{l}$ each for the three sets of primers of the two species and $1 \mu \mathrm{l}$ of $\mathrm{dH}_{2} 0$.}

\section{PCR Cycles}

The reaction steps for the all the above PCR methods include 30 cycles, initial denaturation was done at $94^{\circ} \mathrm{C}$ for 10 minutes, further denaturation at $94^{\circ} \mathrm{C}$ for 1 -minute, annealing $60^{\circ} \mathrm{C}$ for 2 minutes, extension at $72^{\circ} \mathrm{C}$ for 2 minutes and a final extension at $72^{\circ} \mathrm{C}$ for 10 minutes. The positive and negative controls were procured from HELINI Biomolecules, Pvt limited and included with every cycle.

\section{Gel Documentation}

After amplification, the product was kept frozen at $-20^{\circ} \mathrm{C}$ for storage. About $5 \mu \mathrm{l}$ of PCR product was loaded on $1 \%$ agarose gel for electrophoresis, and $0.5 \mathrm{mM} \times \mathrm{TAE}$ running buffer containing $0.05 \%$ Ethidium bromide at $100 \mathrm{~V}$ was run for 1 hour in gel electrophoresis apparatus. The ladder was procured from Takara bio Home, and DNA bands were visualized by UV transillumination with short length light and documented along with the controls.

\section{Statistical Analysis}

Data were analyzed for calculating the percentage of samples positive by microscopy and molecular methods using SPSS version 2.1 .

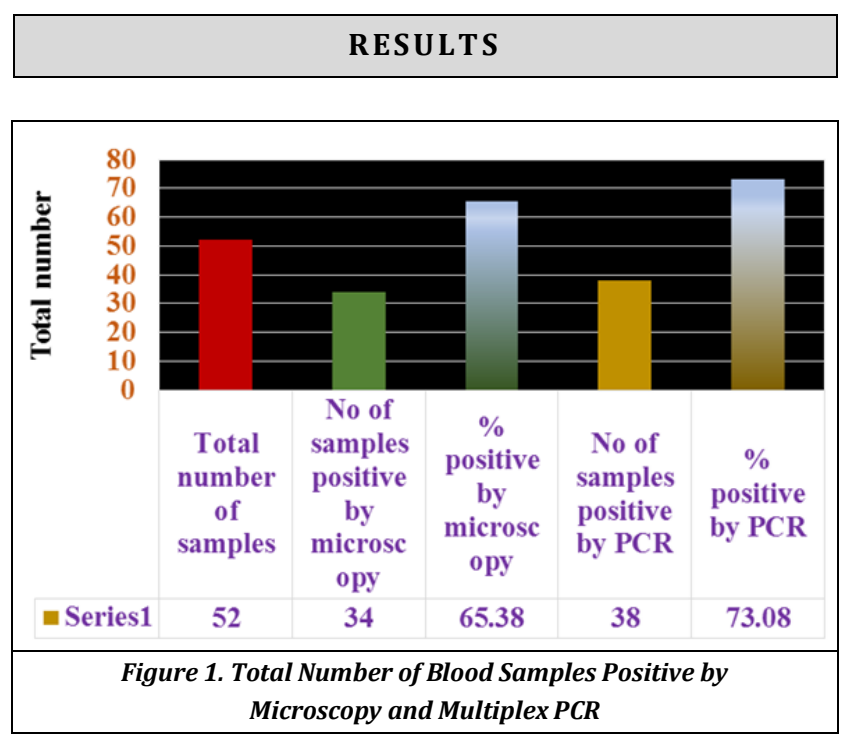

\section{Result Explanation}

[Figure 2] Among the total 52 blood samples collected from suspected clinical malaria cases, 34 were positive by microscopy accounting for $65.38 \%$ and 38 samples were positive by multiplex PCR which was $73.08 \%$, hence molecular method proved to be more sensitive than microscopy. The gel pictures in conventional PCR showed the bands for Plasmodium vivax and Plasmodium falciparum with $833 \mathrm{bp}$ and $1451 \mathrm{bp}$ respectively. The multiplex gel pictures showed the 10 bands positive for Plasmodium falciparum and 38 bands positive for Plasmodium vivax. The gel picture of multiplex PCR standardized by using pooled DNA extracts of two sets showed the presence of two bands at $833 \mathrm{bp}$ for Plasmodium vivax and 1451 bp for Plasmodium falciparum.

\section{DISCUSSION}

The advent of PCR based molecular diagnostics methods for identifying malaria parasite has been producing highly specific and sensitive results. For the detection of Plasmodium species, several research studies have shown to attempt 
amplification methods like conventional nested PCR, seminested and single-step multiplex PCR, the real-time and LAMP assay.(7) In the present study standardization of multiplex PCR was done to detect the four different species of genus Plasmodium by conventional multiplex PCR system in a single tube reaction with appropriate controls. In a study by Lee et al done in 2015 a comparison was done by single-step multiplex PCR with real-time PCR and two panels of multiplex PCR, in his observations he concluded that there are some constraints regarding real-time PCR for diverse species identification, as it missed mixed infections and the presence of biases in amplification of species in severe grade infections,(7) whereas the other, two-panel method of multiplex PCR showed some discordance when compared with sequencing method. Thus, the significance of molecular techniques has become one of the research priorities for the diagnosis of malaria in the future. Even though microscopic methods like Giemsa or Leishman stained smears are gold standard, it is challenging when the parasitaemia levels drop below 40 parasites/ $\mu \mathrm{l}$ of blood and in mixed infections. This limitation can be overcome by conventional PCR assays which can detect as low as 0.004 parasites per microliter. (10) Parasites at low titers of 5 parasites/ $\mu$ l can be detected targeting 18s rRNA genes which have been considered as a molecular gold standard. Several attempts are being made to develop a simpler, single-step reaction mix multiplex PCR system which allows simultaneous identification of Plasmodium species in a single tube reaction.(6) In the present study, about 52 blood samples were collected from the patients with suspected clinical malaria. From the total of 50 blood samples collected, about 38 samples were positive in this multiplex PCR and about 34 were found to be positive by microscopy. Among the 38 blood samples positive by singlestep multiplex PCR reaction mix for various Plasmodium species, 28 were belonging to Plasmodium vivax and 10 were belonging to Plasmodium falciparum by conventional PCR, the same results were produced with the duplex PCR. In our study, about four samples were negative by microscopy indicating the sensitivity of multiplex PCR. In a similar study done by Lee et al in 2015, using a single-step multiplex PCR assay, proved to be a more accurate and reliable method which was confirmed with sequencing methods.

The main limitation of the present study is that the results are to be compared with real-time PCR and sequencing methods to prove the concordance. Multiplex PCR as a novel method for detecting Plasmodium species has many advantages as it is less labour-intensive when compared to microscopic methods especially in field surveys in endemic areas. The time taken for our single-step multiplex PCR is less than 7 hours which is much less when compared to the nested PCR which takes about 20 hours.

\section{CONCLUSIONS}

Attempts in redesigning more economical, less time consuming, sensitive and specific methods of multiplex PCR will be very useful in detecting novel species of Plasmodium causing malaria, as well as to detect resistance patterns exhibited by Plasmodium species which also helps in making appropriate therapeutic decisions.

\section{ACKNOWLEDGEMENT}

Dr. Priyadarshini Shanmugam, MD, PhD., Professor, and Head, Department of Microbiology, Chettinad Hospitals and Research Institute, Chennai.

\section{REFERENCES}

[1] World Health Organization https://www.who.int

[2] Figueiredo MA, Di Santi SM, Manrique WG, et al. Serological and molecular techniques applied for identification of Plasmodium spp. in blood samples from nonhuman primates. Revista Brasileira de Parasitologia Veterinária 2018;27(3):363-76.

[3] Ministry of Health. Health Statistical Year Book. Riyadh (KSA): Dar Al-Hilal Publishing House 2010. http://www.moh.gov.sa/Ministry/MediaCenter/News/ Documents/healthybook.pdf

[4] Petti CA, Polage CR, Quinn TC, et al. Laboratory medicine in Africa: a barrier to effective health care. Clinical Infectious Diseases 2006;42(3):377-82.

[5] Gordon C, Alimuddin Z. Manson's Tropical Diseases. London: Saunders Elsevier, Ltd., 1800.

[6] National Vector Borne Disease Control Programme (NVBDCP), Ministry of Health \& Family Welfare, Government of India Designed and Developed by Center for Health Informatics.

[7] Stanis CS, Song BK, Chua TH, et al. Evaluation of new multiplex PCR primers for the identification of Plasmodium species found in Sabah, Malaysia. Turkish Journal of Medical Sciences 2016;46(1):207-18.

[8] Komaki-Yasuda K, Vincent JP, Nakatsu M, et al. A novel PCR-based system for the detection of four species of human malaria parasites and Plasmodium knowlesi. PloS One 2018;13(1):e0191886.

[9] Saito T, Kikuchi A, Kaneko A, et al. Rapid and sensitive multiplex single-tube nested PCR for the identification of five human Plasmodium species. Parasitology International 2018;67(3):277-83.

[10] Lee PC, Chong ETJ, Anderios F, et al. Molecular detection of human Plasmodium species in Sabah using PlasmoNex ${ }^{\mathrm{TM}}$ multiplex PCR and hydrolysis probes realtime PCR. Malaria Journal 2015;14(1):28.

[11] Chew CH, Lim YA, Lee PC, et al. Hexaplex PCR detection system for identification of five human Plasmodium species with internal control. Journal of Clinical Microbiology 2012;50(12):4012-9.

[12] Lee WJ, Kim HH, Choi YK, et al. Analysis of the dihydrofolate reductase-thymidylate synthase gene sequences in Plasmodium vivax field isolates that failed chloroquine treatment. Malaria Journal 2010;9(1):331. 